\title{
Response to: "T1 Slope in the Cervical Spine Magnetic Resonance Imaging: A Novel Concept"
}

\author{
Seung-Hwan Lee \\ Department of Orthopaedic Surgery, Gwangmyeong Sungae Hospital, Gwangmyeong, Korea
}

Comment:

1. T1 slope was measured as the angle between a horizon tal line and superior endplate of T1 in standing lateral ra $\neg$ diograph of cervical spine[1].

2. Cervical lordosis was measured between lower end plate of C2 and inferior end plate of C7 in the same standing lateral radiograph[2].

3. Cervical intervertebral disc degeneration was measured in T2-weighted sagittal images based on the magnetic resonance imaging-based grad $\neg$ ing system.

4. T1 slope could not be measured in MRI because the subject was in lying position.

5. In our study, patients with low $\mathrm{T} 1$ slope $\left(\leq 25^{\circ}\right)$ in standing lateral radiograph had higher grade of degeneration in cervical MRI than patients with high T1 slope(>25) in C5-6 and C6-7 intervertebral discs[3].

\section{Conflict of Interest}

No potential conflict of interest relevant to this article was reported.

\section{ORCID}

Seung-Hwan Lee: https://orcid.org/0000-0002-0432-3857

\section{References}

1. Knott PT, Mardjetko SM, Techy F. The use of the T1 sagittal angle in predicting overall sagittal balance of the spine. Spine J 2010;10:994-8.

2. Miyazaki M, Hong SW, Yoon SH, et al. Reliability of a magnetic resonance imaging-based grading system for cervical intervertebral disc degeneration. J Spinal Disord Tech 2008;21:288-92.

3. Yang BS, Lee SK, Song KS, et al. The Use of T1 Sagittal Angle in Predicting Cervical Disc Degeneration. Asian Spine J 2015;9:757-61. 